\title{
Determinan Kinerja dan Kompetensi Bidan di Provinsi Sumatera Utara, Nusa Tenggara Timur, Kalimantan Barat, dan Sulawesi Selatan
}

\author{
Performance and Competence Determinants of Midwive in North \\ Sumatera, East Nusa Tenggara, West Kalimantan, and South Sulawesi
}

\author{
Ronald Hutapea
}

Fakultas Ilmu Kesehatan Universitas Respati Indonesia

\begin{abstract}
Abstrak
Kinerja sesungguhnya dari seorang bidan ditentukan oleh beberapa faktor yang berpengaruh sejak masa pendidikan bidan yang ditempuhnya. Banyak variabel yang dapat saling mempengaruhi untuk membentuk kemampuannya dalam menjalankan tugas. Penelitian ini menggunakan pendekatan sistem bertujuan untuk menetapkan korelasi dari beberapa variabel yang terdapat dalam ke-4 komponen pendidikan bidan yakni input, process, output, dan outcome. Dengan cara survei, sebanyak 261 responden dari 4 provinsi yaitu Sumatera Utara, Kalimantan Barat, Sulawesi Selatan, dan Nusa Tenggara Timur diminta untuk menilai kinerja bidan. Selanjutnya, suatu survei mendalam diadakan terhadap 107 bidan untuk meneliti korelasi dari sejumlah variabel yang mempengaruhi proses pendidikannya. Hasil penelitian menunjukkan adanya hubungan bermakna antara kinerja bidan dengan semua aspek dalam sistem pendidikannya. Analisis statistik juga menunjukkan korelasi yang nyata antara kinerja bidan di tempat kerjanya dengan beberapa variabel antara lain sistem rekrutmen, latar belakang sekolah, dan motivasinya. Dapat disimpulkan bahwa sistem pendidikan bidan dewasa ini telah cukup efektif dalam menghasilkan bidan-bidan yang kompeten dan termotivasi. Disarankan pula agar pendidikan bidan di masa mendatang dapat mempersiapkan bidan-bidan kita untuk meningkatkan kompetensinya dalam menghadapi liberalisasi jasa dalam pasar tenaga kerja dunia yang semakin bebas.
\end{abstract}

Kata kunci: Pendidikan kebidanan, kinerja, kompetensi, liberalisasi

\section{Abstract}

Performance in the work place for midwives are determined by several factors in the beginning of their professional education and training. A number of variables interact significantly, resulting in their competence to perform their tasks. This research, based on system approach, aims to determine the correlation and validity of several predictors in 4 components of their midwive education i.e input, process, output and outcome. Using survey methodology, 261 respondents from 4 provinces, North Sumatra, West
Kalimantan, South Sulawesi, and East Nusa Tenggara participated in this survey to rate the midwive's performance. Further on, an indepth survey have been imposed on 107 midwives to study the correlation of some of their background variables. Research result shows significant correlation between midwives performance with all aspects of their education systems. Statistical analysis also shows that midwives performance in the workplace correlates with their recruitment system, training background, and motivation. In conclusion, performances of midwives are perceived to be satisfactory, showing correlation with their motivation and competence. It also suggest that the present training system have been considerably effective to produce competent and motivated midwives. Suggestion for future midwives in training is to prepare themselves for global competence in preparation for service liberalization in the world free market.

Key words: Midwive education, performance, competence, liberalization

\section{Pendahuluan}

Dewasa ini, Indonesia berada pada era globalisasi dan pasar bebas terutama yang berkaitan dengan sektor jasa. Tahun 2015, negara-negara Association of Southeast Asia Nations (ASEAN) menempatkan kesehatan sebagai salah satu sektor prioritas yang akan diintegrasikan ke dalam kerangka Asean Framework Agreement on Services (AFAS)/General Agreement on Trade in Services (GATS). Dalam rangka itu, pada pertemuan The Coordinating Committee on Services (CCS) sejak tahun 2008, ASEAN telah menyepakati akan menandatangani Mutual Recognition Arrangement (MRA) untuk tenaga perawat dan tenaga medis disamping profesi lainnya

Alamat Korespondensi: Ronald Hutapea, Fakultas Ilmu Kesehatan Universitas Respati Indonesia, Jl. Bambu Apus I No. 3 Cipayung Jakarta Timur 13890, Hp.0811882150,e-mail: ronhpea@yahoo.com 
seperti teknisi, arsitektur, surveying, accountancy. MRA akan menjadi dasar penerapan Moda 4 (World Trade Organization, WTO) tentang mobilitas tenaga profesional termasuk tenaga kesehatan. Pembicaraan menuju liberalisasi jasa yang lebih global pada tingkat dunia masih terus berlangsung melalui WTO. Negara kita memiliki potensi yang baik untuk berperan dalam pasar jasa tersebut termasuk tenaga kesehatan. ${ }^{1}$ Namun secara nasional, penyiapan tenaga kerja termasuk bidan ternyata masih belum sinkron. ${ }^{2}$

Saat ini diperkirakan jumlah bidan di Indonesia sekitar 93.885 orang, jumlah lembaga pendidikan kebidanan 465 unit dengan lulusan bidan setiap tahun sekitar 10.000 orang. ${ }^{3}$ Meskipun demikian, tidak seluruh lulusan bidan dapat dimanfaatkan secara optimal karena menyangkut formasi dan pembiayaan. Pengalaman membuktikan bahwa dari tahun ke tahun hanya sekitar $10 \%$ dari lulusan bidan yang dapat diserap oleh pemerintah. ${ }^{4}$ Peluang tenaga bidan untuk bekerja di manca negara pada era pasar bebas tersebut sangat besar dan merupakan tantangan yang perlu diperjuangkan secara sungguh-sungguh di masa mendatang. Untuk itu, perlu dicermati kurikulum pendidikan bidan kita masih belum siap dalam mengantisipasi peluang tersebut. ${ }^{5}$ Agar tenaga bidan Indonesia tidak kalah bersaing dengan bidan dari negara-negara lain, untuk pasar kerja dalam negeri dan luar negeri, bidan Indonesia perlu memiliki kompetensi yang setara atau lebih tinggi daripada bidan dari negara-negara lain. Jasa bisnis oleh tenaga bidan didalam klasifikasi internasional termasuk dalam CPC 93191 berupa jasa yang disediakan oleh bidan, perawat, fisioterapis, dan tenaga paramedis.

Upaya meningkatkan kualitas pelayanan ibu dan anak sangat penting karena berkaitan langsung dengan masalah kesejahteraan keluarga dan masa depan bangsa. Seiring dengan perkembangan sosial ekonomi masyarakat, permintaan untuk pelayanan kesehatan juga semakin meningkat terutama dari aspek kualitatif. Dengan pelayanan kesehatan ibu dan anak yang pada dasarnya terkait langsung dengan pencetakan generasi masa depan, diharapkan dapat tumbuh generasi muda bangsa yang sehat dan kuat. Peran bidan sebagai pelaku utama pelayanan kesehatan pada masa reproduksi dalam siklus kehidupan perempuan, memiliki kompetensi yang meliputi asuhan pada prahamil, kehamilan, persalinan, ibu postpartum/menyusui, bayi baru lahir, balita sehat, kesehatan reproduksi perempuan dan keluarga berencana, serta asuhan kebidanan di komunitas yang dilakukan secara mandiri, kolaborasi dan atau merujuk. Oleh sebab itu, mutu kompetensi bidan dalam memberikan pelayanan harus selalu terjaga. ${ }^{6}$

Dalam kerangka Pembangunan Nasional tahun 20042009, pembangunan kesehatan merupakan salah satu agenda utama Mewujudkan Indonesia yang Sejahtera, yaitu Peningkatan Akses terhadap Layanan Kesehatan yang Berkualitas. ${ }^{7}$ Sasaran pembangunan kesehatan yang akan dicapai pada akhir tahun 2009 adalah: 1) meningkatkan umur harapan hidup dari 66,2 tahun menjadi 70,6 tahun; 2) menurunkan angka kematian bayi dari 35 menjadi 26 per 1.000 kelahiran hidup; 3) menurunkan angka kematian ibu melahirkan dari 307 menjadi 226 per 100.000 kelahiran hidup serta 4) menurunkan prevalensi gizi kurang pada balita dari $25,8 \%$ menjadi $20 \% .{ }^{7}$ Untuk pencapaian sasaran tersebut, diperlukan dukungan sumber daya kesehatan yang memadai, tersedia dalam jumlah yang cukup, terdistribusi sesuai dengan kebutuhan serta berkualitas. Dalam pengembangan desa siaga, di setiap desa harus tersedia tenaga kesehatan, antara lain tenaga bidan yang tidak saja dapat memberikan pelayanan kesehatan, tetapi juga mampu melakukan fasilitasi dalam pemberdayaan masyarakat di bidang kesehatan.

Tindakan untuk mencapai pengurangan kematian anak harus mencakup kepastian pencapaian program cakupan imunisasi, suplemen vitamin A, peningkatan air susu ibu (ASI) eksklusif untuk anak di bawah 6 bulan, ASI dan makanan pendamping ASI yang tepat untuk anak usia 6 bulan sampai 2 tahun; promosi mencuci tangan dan pengolahan air minum; mengutamakan sosial ekonomi rendah yang menyebabkan kematian anak, yakni akses ibu terhadap kesehatan reproduksi, pendidikan, dan pekerjaan; mencegah dan memberikan pengobatan yang efektif terhadap pneumonia, diare, malaria, dan penyakit menular lainnya; serta promosikan sistem pelayanan kesehatan primer yang komprehensif dan menyeluruh dengan keterlibatan petugas kesehatan disertai dengan pelayanan kesehatan berkelanjutan dan program pendidikan perempuan.

Tujuan untuk meningkatkan kesehatan ibu antara lain melindungi wanita hamil dari kekerasan dalam rumah tangga; melibatkan pria dalam kesehatan ibu dan kesehatan reproduksi; meningkatkan akses terhadap kontrasepsi serta konseling kesehatan seksual dan reproduksi, baik untuk pria, wanita, dan remaja; meningkatkan upaya untuk mencegah perkawinan anakanak dan memastikan bahwa wanita usia muda menunda kehamilan pertama mereka.

Tujuan pengkajian kinerja tenaga kesehatan kebidanan ini adalah memberikan gambaran nyata tentang hasil proses pendidikan Program Diploma Kebidanan untuk digunakan sebagai bahan masukan untuk penyelenggaraan Pendidikan Tenaga Kesehatan (Diknakes) yang lebih baik.

\section{Metode}

Penelitian dilakukan di provinsi Sumatera Utara, Nusa Tenggara Timur, Kalimantan Barat, dan Sulawesi Selatan pada bulan Oktober-November 2006. 


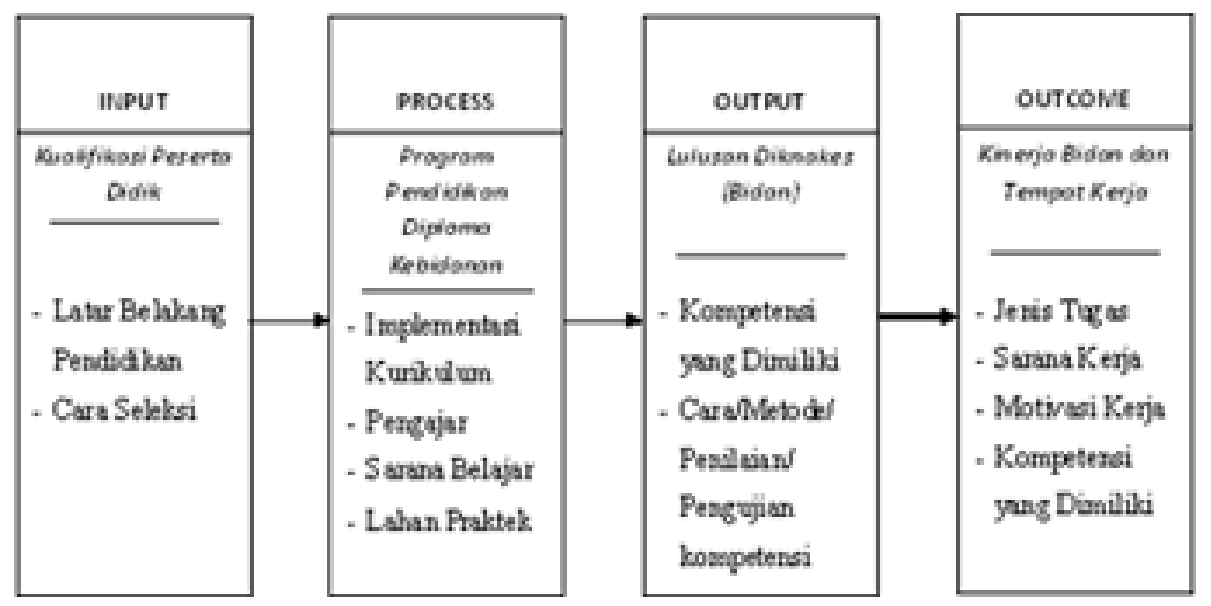

Gambar 1. Alur dan Keterkaitan Antarsubsistem

Pendekatan yang digunakan dalam mengkaji kinerja tenaga bidan adalah pendekatan sistem (system approach) yang meliputi 4 komponen atau subsistem yang saling berkaitan meliputi masukan, proses, luaran, dampak dan setiap komponen ditentukan oleh beberapa faktor. Komponen masukan meliputi faktor-faktor latar belakang pendidikan dan cara seleksi; komponen proses meliputi faktor-faktor kurikulum, pengajar, dan sarana belajar termasuk lahan praktek; komponen luaran meliputi faktor-faktor cara/metode penilaian/pengujian dan kompetensi yang dikuasai. Komponen dampak meliputi faktor-faktor jenis tugas yang diberikan, sarana kerja yang tersedia, motivasi kerja, dan kompetensi yang dimiliki (Lihat Gambar 1).

Metode pengumpulan data meliputi pengumpulan data primer survei yang menggunakan metode wawancara terstruktur dan sumber data sekunder dokumen, laporan-laporan, dan arsip. Data primer diperoleh dari responden melalui pengisian kuesioner dan wawancara. Responden adalah bidan, supervisor bidan, dosen, pimpinan lembaga pendidikan, dan dinas kesehatan. Penetapan sampel responden menggunakan teknik purposive random sampling. Variabel yang diteliti meliputi kinerja bidan dan kinerja lembaga pendidikan. Kinerja bidan meliputi kompetensi yang dimiliki, sarana kerja yang tersedia, motivasi kerja, dan jenis tugas yang dikerjakan. Kinerja lembaga pendidikan meliputi kompetensi pengajar/dosen, sarana belajar yang tersedia, kurikulum pendidikan serta cara/metode penilaian/pengujian. Data kualitatif yang diperoleh ditransformasikan ke dalam data kuantitatif sehingga dapat dianalisis secara kuantitatif dengan metode statistik. Setiap jawaban responden diberi kode tertentu dengan menggunakan skor skala linkert. Analisis data dilakukan dengan analisis univariat untuk mendeskripsikan kinerja bidan yang bekerja di pelayanan kesehatan dan mendeskripsikan kinerja lembaga pendidikan bidan. Analisis bivariat dilakukan untuk menggambarkan hubungan masing masing subvariabel dalam kinerja lulusan dengan subvariabel kinerja lembaga pendidikan. Analisis multivariat dilakukan untuk mendeskripsikan subvariabel yang paling berhubungan antara kinerja lulusan dengan kinerja lembaga pendidikan. Untuk mengetahui pengaruh antarvariabel digunakan analisis jalur (path analysis) yang meliputi langkah-langkah kinerja bidan (X), terdiri dari: kompetensi bidan (X1), sarana kerja (X2), motivasi kerja (X3), dan jenis tugas $(\mathrm{X} 4)$. Kinerja lembaga pendidikan ( $\left.\mathrm{Y}^{\prime}\right)$, terdiri dari: kompetensi dosen (X1'), sarana belajar (X2'), kurikulum pendidikan (X3'), cara/metode penilaian/ pengujian (X4'), dan menghitung koefisiensi korelasi.

\section{Hasil}

\section{Lokasi dan Sebaran Responden}

Lokasi dan sebaran responden dilakukan di 4 provinsi yaitu Sumatera Utara, Sulawesi Selatan, Kalimantan Barat, dan Nusa Tenggara Timur. Sedangkan data jumlah responden yang dijadikan sampling untuk tiap-tiap provinsi (Lihat Tabel 1).

\section{Analisis Bivariat}

Berdasarkan data tersebut dapat dilihat bahwa ada hubungan antara variabel sistem belajar mengajar, pendidik/pengajar, sarana dan prasarana termasuk lahan praktek serta lingkungan belajar dengan kepuasan kinerja bidan. Ada hubungan antara variabel cara seleksi, 
Tabel 1. Lokasi dan Sebaran Responden

\begin{tabular}{|c|c|c|c|c|c|c|c|c|c|}
\hline \multirow{2}{*}{ Provinsi } & \multicolumn{4}{|c|}{ Bidan } & \multirow{2}{*}{ Pasien } & \multirow{2}{*}{ Atasan } & \multirow{2}{*}{ Pimpinan } & \multirow{2}{*}{ Dosen } & \multirow{2}{*}{ Jumlah } \\
\hline & RSU & $\mathbf{K B}$ & Puskesmas & Mandiri & & & & & \\
\hline Sumatera Utara & 12 & 10 & 10 & 10 & 42 & 7 & 7 & 7 & 105 \\
\hline Sulawesi Selatan & 8 & 8 & 8 & 8 & 32 & 4 & 4 & 4 & 76 \\
\hline Kalimantan Barat & 7 & 5 & 5 & 5 & 22 & 3 & 3 & 3 & 53 \\
\hline Nusa Tenggara Timur & 3 & 3 & 3 & 3 & 12 & 1 & 1 & 1 & 27 \\
\hline Total & 30 & 26 & 26 & 26 & 108 & 15 & 15 & 15 & 261 \\
\hline
\end{tabular}

Tabel 2. Hasil Analisis Bivariat Variabel Individu, Kontekstual, Status Lembaga dengan Kepuasan, Motivasi, dan Kompetensi

\begin{tabular}{|c|c|c|c|}
\hline \multirow{2}{*}{ Variabel Independen } & \multicolumn{3}{|c|}{ Nilai p } \\
\hline & Kepuasan & Motivasi & Kompetensi \\
\hline \multicolumn{4}{|l|}{ Faktor individu } \\
\hline Umur & 0,352 & 0,685 & 0,472 \\
\hline Lama kerja & 0,344 & 0,578 & 0,028 \\
\hline Sumber pembiayaan & 0,422 & 0,184 & 0,569 \\
\hline \multicolumn{4}{|l|}{ Faktor kontekstual } \\
\hline Cara seleksi & 0,102 & 0,004 & 0,330 \\
\hline Sistem belajar mengajar & 0,135 & 0,616 & 0,465 \\
\hline Kurikulum pendidikan & 0,774 & 0,224 & 0,126 \\
\hline Pendidik/pengajar & 0,000 & 0,778 & 0,420 \\
\hline Sarana dan prasarana & 0,000 & 0,000 & 0,132 \\
\hline Lingkungan belajar & 0,000 & 0,000 & 0,249 \\
\hline Status lembaga pendidikan (negeri/swasta) & 0,475 & 0,251 & 0,126 \\
\hline
\end{tabular}

sarana dan prasarana termasuk lahan praktik serta lingkungan belajar dengan motivasi kinerja bidan. Berdasarkan data diatas dapat dilihat bahwa ada hubungan antara variabel lama kerja dengan kompetensi kinerja bidan. Variabel yang menjadi kandidat dalam analisis multivariat adalah yang memiliki $p$ value $<0,25$ (Lihat Tabel 2).

\section{Analisis Multivariat \\ Kepuasan}

Berdasarkan hasil analisis terlihat bahwa signifikansi $\log$-likehood $<0,005(\mathrm{p}=0,036)$. Namun, $p$ Wald $>$ 0,005 perlu dilakukan pengeluaran variabel dari model. Pengeluaran variabel dilakukan secara bertahap satu per satu dimulai dari variabel $p$ value tertinggi. Terlihat bahwa variabel sarana mempunyai $p$ value yang besar sehingga proses model selanjutnya tidak mengikutkan variabel sarana. Hasil model tanpa variabel sarana terlihat bahwa signikansi log-likehood $<0,005$ ( $\mathrm{p}=$ 0,014). Namun secara signifikan, $p$ Wald (SIG) yang variabelnya $p>0,005(0,996)$ sehingga tidak dapat diketahui diantara kedua variabel tersebut variabel mana yang sangat mempengaruhi kepuasan (Lihat Tabel 3).

\section{Motivasi}

Berdasarkan hasil analisis terlihat bahwa signifikansi log-likehood $>0,005(p=0,758)$. Namun pengeluaran variabel dilakukan secara bertahap satu per satu dimulai dari variabel $p$ value tertinggi. Pada hasil terlihat bahwa variabel cara seleksi mempunyai $p$ value yang besar sehingga proses model selanjutnya tidak mengikutkan variabel cara seleksi. Hasil model tanpa variabel cara seleksi terlihat bahwa signifikansi log-likehood $>0,005(\mathrm{p}=$ $0,859)$ dan secara signifikan $p$ Wald (SIG) yang variabelnya $p>0,005(0,999)$. Hal ini berarti antara variabel sarana dan lingkungan belajar tidak dapat diketahui variabel yang paling dominan mempengaruhi motivasi (Lihat Tabel 4).

\section{Pembahasan}

Dilihat dari aspek masukan, modal dasar seorang calon bidan cukup besar. Pertama, sebagian besar mereka mengikuti pendidikan kebidanan karena minat. Hal ini dapat dilihat dari sumber pembiayaan yang 
Tabel 3. Analisis Multivariat Pendidik, Sarana, dan Lingkungan Belajar dengan Kepuasan

\begin{tabular}{llllll}
\hline \multicolumn{1}{c}{ Variabel } & \multicolumn{1}{c}{ B } & OR & -2 log likelihood & G & Nilai p \\
\hline Pendidik/pengajar & 18,163 & 7,7304 & 2,773 & 8,564 & 0,036 \\
Sarana dan prasarana & 0,012 & 1,012 & & \\
Lingkungan belajar & 17,330 & 3,36027 & & & \\
\hline
\end{tabular}

Tabel 4. Analisis Multivariat Pendidik, Sarana, dan Lingkungan Belajar dengan Motivasi

\begin{tabular}{llllll}
\hline \multicolumn{1}{c}{ Variabel } & B & OR & -2 log likelihood & G & Nilai p \\
\hline Cara seleksi & 18,258 & 8,5024 & 7,941 & 3,396 & 0,758 \\
Sarana dan prasarana & 16,372 & 0,000 & & \\
Lingkungan belajar & 15,499 & 0,000 & & & \\
\hline
\end{tabular}

berasal dari biaya sendiri. Oleh sebab itu, motivasi belajar dan motivasi bekerja relatif lebih kuat dibandingkan dengan mereka yang mengikuti pendidikan bidan karena beasiswa atau bantuan lain. Kedua, sebagian besar mereka memasuki pendidikan kebidanan dengan proses seleksi yang relatif ketat sehingga peserta pendidikan kebidanan sebenarnya adalah individu yang terpilih. Dengan demikian, seorang bidan pada dasarnya adalah individu yang mempunyai motivasi dan dasar kemampuan yang kuat. Aspek motivasi ternyata sejak dulu merupakan prediksi dominan kinerja bidan dan telah diteliti di berbagai wilayah tanah air. Sedangkan faktor-faktor individu yang lain seperti umur, asal, dan status marital terbukti kurang signifikan. ${ }^{8-10}$

Dilihat dari aspek proses, sistem pendidikan bidan sebenarnya sudah cukup memadai. Hal ini dapat dilihat dari sistem belajar mengajar, kemampuan pengajar, sarana dan prasarana pendidikan. Pertama, proses belajar lebih banyak didasarkan atas keseimbangan teori dan praktek. Kedua, kemampuan pengajar dinilai baik, dan ketiga, sarana dan prasarana untuk proses pendidikan juga sangat mendukung. Dengan melihat ketiga hal tersebut, proses pendidikan sebenarnya telah berjalan sesuai dengan yang diharapkan. Pengembangan kurikulum mengacu kepada standar kompetensi kebidanan yang diakui secara internasional. ${ }^{11-15}$

Berdasarkan aspek keluaran, lulusan pendidikan bidan telah memiliki kesiapan untuk bekerja dengan baik. Hal ini dapat dilihat dari motivasi dan kompetensi yang dimilikinya. Pertama, hampir semua bidan memiliki motivasi kerja yang tinggi. Motivasi ini dibangun karena minat dan semangat untuk mengabdi. Kedua, pada saat memasuki dunia kerja, para bidan telah dibekali dengan kompetensi yang memadai. Hal ini terutama dihasilkan dari proses pendidikan yang memadai pula. Bertitik tolak dari kedua hal tersebut, proses pendidikan yang ada sebenarnya telah menciptakan seorang bidan yang siap kerja.

Berdasarkan aspek kinerja, sebagian besar para bidan memiliki kinerja yang baik. Hal ini terutama diukur dari kepuasan pasien dan pimpinan tempat kerja. Kepuasan pasien dan pimpinan tempat kerja yang mencerminkan kepuasan pengguna jasa (user) merupakan kriteria utama dalam menilai kinerja bidan. Kenyataan yang ada menunjukkan bahwa para pengguna menilai pelayanan dan kerja para bidan sesuai dengan keinginan atau harapan mereka.

Secara keseluruhan, kinerja bidan di tempat kerja sangat dipengaruhi oleh sistem rekrutmen calon bidan, sistem pendidikan bidan, dan kualitas dari lulusan pendidikan bidan. Hal ini berarti bahwa kinerja bidan yang baik di tempat kerja sangat terkait dengan tahapantahapan sebelumnya. Walaupun demikian, terdapat beberapa faktor yang dapat meningkatkan kualitas dari kinerja bidan, diantaranya adalah kondisi atau iklim kerja. Dengan iklim kerja yang semakin kondusif, para bidan dapat bekerja lebih optimal. Secara khusus kinerja bidan sangat dipengaruhi oleh motivasi dan kompetensi yang dimilikinya. Kompetensi yang memadai yang didukung oleh motivasi kerja yang kuat menjadi aspek yang paling dominan pada kinerja bidan. ${ }^{16}$

\section{Kesimpulan}

Secara keseluruhan, kinerja bidan dinilai baik. Hal ini disebabkan karena bidan memiliki motivasi dan kompetensi yang memadai. Secara keseluruhan, kinerja bidan yang baik dipengaruhi oleh proses pendidikan yang dinilai baik. Proses pendidikan kebidanan yang ada sekarang dinilai memadai baik dilihat dari sistem pengajaran maupun dukungan sarana. Untuk memberikan pelayanan yang lebih baik kepada masyarakat terutama di dalam era globalisasi, kualitas 
pelayanan dari bidan dan tempat usahanya harus lebih ditingkatkan. Hal ini dikaitkan dengan liberalisasi pelayanan kesehatan di kawasan ASEAN dan di tingkat global. Untuk meningkatkan kualitas bidan yang lebih kompetitif didalam konteks liberalisasi jasa kesehatan di kawasan ASEAN maka kualitas lembaga pendidikan kebidanan perlu ditingkatkan, paling tidak setara dengan negara-negara lain di kawasan ASEAN.

\section{Saran}

Dalam konteks kondisi masyarakat masa mendatang terutama dikaitkan dengan liberalisasi sektor jasa kesehatan di kawasan ASEAN, kinerja bidan dan kinerja lembaga pendidikan kebidanan perlu ditingkatkan. Kerja sama antarnegara di kawasan ASEAN pada masa mendatang dalam berbagai aspek termasuk pendayagunaan tenaga profesional diharapkan lebih nyata melalui kerja sama dengan United Nations (UN). Untuk itu, perlu upaya lebih jauh mempersiapkan kompetensi tenaga kerja profesional tersebut. Perlu beberapa langkah perubahan yang mendasar. Perlu dikembangkan kurikulum berbasis kompetensi dengan standar internasional pada tataran kurikulum pendidikan kebidanan. Perlu upaya mendidik kembali para tenaga pengajar melalui kegiatan pendidikan lanjutan dan atau magang di luar negeri. Perlu dikembangkan sistem uji dan sertifikasi kompetensi yang mengacu kepada sistem nasional dan atau internasional pada tatanan sistem pengujian. Perlu dikembangkan atau dibentuk lembaga sertifikasi profesi kebidanan oleh para pemangku kepentingan khususnya asosiasi profesi bidan dan asosiasi pendidikan kebidanan.

\section{Daftar Pustaka}

1. Bartlett P, Kelaher D. Kepentingan Indonesia di berbagai perundingan perdagangan internasional jasa kesehatan. Jakarta: Kementerian Perdagangan Republik Indonesia; 2009.
2. Imron MB. Penyiapan tenaga kerja di era global: relevansi pendidikan dan kebutuhan pasar kerja masih mismatch. Penduduk dan Pembangunan XII. 2001; 2.

3. The World Bank. Indonesia's doctors, midwives, and nurses: current stock, increasing needs, future challenges, and options. 2009.

4. Cumberford J. Health human resources and service outcomes. Jakarta: Consultant Report World Bank; 2003.

5. Hutapea R. Kurikulum kita belum memenuhi standar internasional. Jakarta: Bina Diknakes 42; 2002.

6. Bascom World. Peran dan fungsi bidan. 2009. Diunduh dari: http:// www.bascommetro.com.

7. Badan Perencanaan Pembangunan Nasional. Rencana PembangunanJangka Menengah (RPJM) Nasional 2004-2009.

8. Haslinda. Faktor-faktor yang berhubungan dengan prestasi kerja bidan di desa [tesis]. Jakarta: Program Pasca Sarjana Universitas Indonesia; 1994.

9. Nirwana. Analisis faktor-faktor yang berhubungan dengan kompetensi bidan dalam pelayanan pertolongan persalinan [tesis]. Jakarta: Program Pasca Sarjana Universitas Indonesia; 2008.

10. Retnasih N. Berbagai faktor yang berhubungan dengan kinerja bidan puskesmas Kabupaten Garut [tesis]. Jakarta: Program Pasca Sarjana Universitas Indonesia; 1995.

11. The United Nation. Striving together, ASEAN and The UN. Publication ISBN: 978-974-680-275-8 ST/ESCAP/2585. 2010.

12. Avery MD. The evolution of the core competencies for basic midwifery practice. Journal of Midwifery and Women's Health. 2000; 45: 532-6.

13. Glover P. ACMI competency standards for midwives: what they mean for your practice. ACMI Journal. 1999; 12: 12-7

14. World Health Organization. Nursing and midwifery education in the twenty-first century. Report of an Intercountry Consultation Bangkok, Thailand, 20-24 December 1999 WHO Project: ICP OSD 001 World Health Organization Regional Office for South-East Asia New Delhi

15. UKCC. Education for change, change for midwifery education. British Journal of Midwifery. 1999; 10: 605-6.

16. Chia SY. Free flow of skilled labor in the ASEAN economic community Singapore institute of international affairs. 2010. Available from: http://www.eria.org/pdf/research/y2010/no3/Chapter4.pdf. 